\title{
A Study on the Creation of Urban Mural in Xi'an under the Background of Silk Road Economy
}

\author{
Fang $\mathrm{Li}$ \\ Xi'an University School of Art 710065
}

Keywords: Urban moral; Art; Creation

\begin{abstract}
Mural art occupies a very important position in China's art history. In Xi'an, an ancient capital with a long history and rich culture, the urban mural art also has a very long history. This paper describes and analyzes the history and development of urban mural art in Xi'an and briefly analyzes the artistic creativity.
\end{abstract}

\section{Introduction}

The mural art occupies a very important position in China's art history. Some scholars regard murals ad the backbone and essence of Chinese painting. After more than two thousand years of development, mural has already been closely related to customs in people's life.

Broadly speaking, paintings on the walls of the building or on the rocks, as well as other murals on the wall of the cave, patterns, can be called murals, and painted on the wall of the painting, also known as "rock painting." Mural paintings on the building can be roughly divided into rough murals, brush murals, painted murals, relief mural, mosaic murals and other craft material murals and so on. The traditional brush murals are divided into wet frescoes and dry frescoes. Ancient Chinese frescoes are generally distinguished by the different places of painting. There are shop frescoes, temple frescoes, grotto murals, tomb murals, residential murals and so on. The main purpose of modern mural is architectural decoration, coordination with buildings and the surrounding environment, fusion is the most important, more diversified materials, with more durable durability.

While discussing the fine traditions of China, Mr. Lu Xun specially emphasized on learning Han sculpture, Tang painting and Song painting. These art forms were more or less from Chinese murals. After the Song and Yuan Dynasties, the literati freehand ink painting began to develop, and paper was widely used in painting. Chinese paintings were transferred from walls to paper and Chinese painting gradually formed. It was no exaggeration to say that the profound history of Chinese painting originated from walls.

\section{Development of Mural in China}

The earliest mural history seems to begin from the rock paintings and cave mural. In the third century BC, China's Warring States Period has been recorded in "Han Fei Zi", as well as the Han Dynasty Sima Qian's "Historical Records", the Northern Wei Dynasty Li Daoyuan "Waterways", are described some of the rock paintings. At present, most scholars believe that the images of rock paintings are mainly used for memorials and the budding of early writing. It is the most primitive "stone wall culture" of mankind. The rock paintings in the north and south of China are dominated by hunters, bows and arrows, animals and plant images, which can be seen for the purpose of seeking survival. Their chronologies are related to reproduction and witchcraft in the early Neolithic period, With some of the more abstract graphic metaphor inversion and the wisdom of worship, these murals were produced roughly in the Neolithic Age, around 4000 BC [1].

At the end of the primitive society, the clan communes began to disintegrate, the phenomenon of 
uneven inequality became more and more obvious, private ownership gradually emerged. Chinese history entered into the Xia, Shang and Zhou period, and the slavery society began.

Xia Dynasty is the first dynasty in our history, and from Yu to Jie, there were altogether seventeen emperors. The capital is frequently moved because the social and economic structure is still dominated by animal husbandry. Xia culture has been more mature that pottery production, jade, stone, bone and textile technology were greatly developed. According to "Shangshu" records, this period of "building palace, decorated Ruitai", you can imagine its architectural murals have begun to take shape. Xia and Shang dynasties, the casting of bronze has reached a considerable level, decorative patterns are more abundant. At that time, the establishment of the monarchy requires political stability, the role of the great ethnics, so artifacts and mural art began to take part of the role of public awareness of the community.

In the Warring States period, with the development of the building, mural art also prospered. From the Zhou Dynasty to Han Dynasty, pavilion murals were rather developed. "Confucius Jia Yu" recorded in the year Confucius visited the Zhou Dynasty hall, seen mural content, like Yao and Shun Jie Zhou", and the "shape of good and evil". These records are not enough to make us understand the whole picture and characteristics of mural art at the time, but at least Zhou Dynasty theme is historical murals, this art form is the ruling class to as propaganda tools, educational tools, plays the "adult education, human" role. There is a grand blueprint, and then the form of buildings, and the lack of internal and external decoration of the mural, which is a kind of art. But China's historical tradition, are often seen as the shape of the process and put them into menial work, very few historical records, so the mural achievement, only a few isolated words and phrases of comment, even so, these descriptions are often simple and abstract, full of exaggerations.

At that time the princes of the palace are very particular about, Wei, Yan, Zhao, Lu, Chu have their own characteristics. One of the most famous is Qi, Qi capital was located at Linzi, Zibo, Shandong, which at that time continued construction of the history of 630 years, the town of strict and large, there is a complete city, palaces in Taiwan Pavilion. Qi are the walls of the ruins still can see traces, some in the actual record of the famous buildings have also been found in the base site. From the excavations have been unearthed pattern brick, tile and other building components can be seen at the time of the magnificent construction scale, decorative gorgeous, causing Qin's attention. Shaanxi unearthed in the Qin and Han bricks, tile of the decorative pattern is clearly learning the former, so that the construction of Qin and murals has been improved.

Decorative murals in the Han Dynasty in China originated in the Western Han Dynasty and became popular in the Eastern Han Dynasty. Most of the tomb owners were high dignitaries or local tyrannies. Murals in Han Dynasty were of great importance to understand the development of economy, culture, society and aesthetic thought in the Han Dynasty.

The Tang Dynasty is the heyday of feudal society in China. The economic and cultural development is highly developed. As a fresco creation of cultural and artistic products, it has also reached an unprecedented height. It is the flourishing period of Chinese ancient frescoes. According to the records, in the 206 well-known painters in the Tang Dynasty, 110 people participated in the fresco creation, they in the two Beijing (Xi'an, Luoyang) area of the palaces, courtyards, houses, temples, Taoist wall of the brush freely, draw a lot mural. However, with the changes of the times and the impact of war, many murals have long gone, only the grotto temple murals and tomb murals to be preserved, especially the Tang Dynasty emperor mausoleum and its burial tombs in the murals, due to long buried In the ground, basically no natural and man-made disturbance and destruction, so the picture is very bright, real and vivid and cannot be compared by other types of murals [3].

During the Song Dynasty, the culture was more developed, philosophical science rose, Buddhism, Taoism, Buddhism and Buddhism merged. Song Dynasty literature and prose as the representative of the Song Dynasty literature has made great achievements. As the royal family and the literati's hobby and attention, secular art and court painting reached unprecedented prosperity during this period. In 
addition, after the mid-Song Dynasty, literati painting rise, against the realism and fine work, the famous painters have quit mural creation, to the ink painting, so that ink painting development, and temple fresco began to decline [4]. The existing Song Dynasty murals are almost all the Northern Song Dynasty, mainly temple murals and tomb murals.

Murals in the Yuan Dynasty mainly include religious murals, tomb murals and palace murals. Among them, there is the largest number of religious murals with the highest levels. Rulers of the Yuan Dynasty firmly believed in religion, so they adopted the coexistence and margining policy for various religions to maintain their spiritual domination. Therefore, all religions and sectors were alive, and Taoism and Buddhism occupied the predominant position [5]. Due to the evolution of burial customs and changing social atmosphere in Ming and Qing Dynasty, the number of murals declined sharply and the artistic level of murals was also not as high as before [3].

\section{Current Development of Urban Mural in Xi'an}

"Eight rivers divert around Chang'an, which is the ancient birthplace of numerous emperors". Xi'an, also known as Chang'an in ancient times, is one of the important birthplaces of the Chinese nation and Chinese culture. A lot of traditional mural heritages are reserved in Xi'an, so in the urban design, planning and construction, great importance is also paid to inheriting and developing traditional culture. In Xi'an, art works combining tradition and modern elements can be seen everywhere [6]. Refreshing mural works can also been seen in Furong Garden in the Tang Dynasty and the Wild Goose Pagoda. In terms of cultivating mural talents, Xi'an Academy of Fine Arts vigorously cooperates with many colleges and universities to establish a mural application talent center to study the mural works in each period and design many mural works rich in characteristics of the times. In the beginning of constructing the Xi'an Metro Line 1, some people and scholars suggested combine the subway station with the museum, but it is not implemented considering the demand to evacuating the crowd. Therefore, the station design will fully take into account the atmosphere with the historical and cultural city of the factors, drawing on the Moscow subway art and Guangzhou, Nanjing, Hong Kong and other places of urban rail transit modernization process, each station by the designer carefully build, Generous simple, full of artistic temperament. Metro Line 1 murals design, the landscape will be combined with the underground fresco, subway station name and historical palm together into one, historical and cultural elements at the same time integration, to create a refreshing, memorable mural art subway hall: "Yuxiang door" subway station murals, the background is the ancient city of Xi'an, the main body is to rescue the people of Xi'an in the fire and water of the famous patriotic general Feng Yuxiang general holding telescope meditation; "sprinkle the bridge" subway station murals, the background is arch bridge, "Changle slope" subway station murals, the main screen is the Xi'an people to carry out cultural and recreational activities of the scene; "Chan River" subway station, the background is the same as the background of the " The wind is moving Yiyi Tsui and the river boat, the main body is an ancient man holding a horse and his wife and children folded Liu Xi other touching scenes; "Banpo" subway station murals, the main content is half of the pots unearthed pots Pottery and the famous "crow's feet" pattern; "Textile City" subway station where the modern textile workshop and Peony printed cloth pattern. These murals not only show the long history of Xi'an, but also reflect the modern city of Xi'an as a modern fashion as well as its avant-garde atmosphere.

\section{A Study on the Artistic Creation of Xi'an Urban Mural under the Background of Silk Road Economy}

The Silk Road Economic Zone is an area of economic cooperation between China and the West Asian countries, roughly covering the ancient Silk Road, including five provinces: Shaanxi, Gansu, Qinghai, Ningxia and Xinjiang Uygur Autonomous Region and four provinces in Southwest China: 
Chongqing, Sichuan, Yunnan and Guangxi. It was proposed by China's Chairman Xi Jinping at the speech delivered at the Kazakhstan Nazarbayev University in 2013. This region contains rich resources, so to construct the Silk Road Economic Zone will have an important impact on the world's economy. Xi'an is the starting point of the ancient Silk Road, so it is an urgent issue for each artist to give play to the cultural advantages of Xi'an, and improve the city's image through art works like murals and promote the coordinated development of economy and the society under the background of constructing the Silk Road Economic Zone. In the construction of urban culture, urban murals play a more and more important role. Mural works appear at various places: church, hotel, station, wharf, airport, subway, school, public cultural square, building façade and ancient tourist destinations. They cannot only highlight the beauty and style of the architectural forms, but also give spirit to the public space, activate the atmosphere and make the venue more attractive. To demonstrate mural works can also play the role of propaganda and cultural communication, which not only adjust people's psychology and inspire them to pursue more ideal life, but also improve the cultural taste of a city's public environment and promote the development of a city's tourism industry and entertainment industry. Thus, mural works play a huge role in the construction of public space. They are regarded as the most suitable forms of art expression spreading cultural information at urban public space in addition to urban sculpture. With rich connotation, they are suitable for creative interpretation of various themes.

In foreign countries, urban murals are applied relatively earlier and more extensively. They are scattered at every corner in the city, making people feel a beautiful environment and get spiritual enjoyment. Meanwhile, they advocate politics, reflect the social hot topics and realize the function of social education. Between the 1920s to the 1930s, Mexican artists gradually engaged themselves in the creation of street murals. Because revolution is the source of inspiration for Mexican mural artists, Mexican mural art is also called the "Mural Movement". It is a reflection of Mexica's national independence struggle and the 1910 Revolution in art as well as the inheritance of traditions in Mayan culture [7]. In the 1960s and the 1970s, due to the development of environmental protection and the promulgation of a series of environmental protection policies, street scenery murals promoting environmental protection began to flourish on the west coast of North America. A series of magnificent "Gray Whale" murals were distributed in all towns of Vancouver. They are not only the city's decoration, but can also commemorate the living process of gray whales from being endangered to survival, arousing people's awareness to protect the environment [8]. The most famous was located at the Gran Vaughan Bridge in downtown Vancouver, occupying a whole wall of a building. In this mural, whale, the sea and reddish-brown walls are very eye-catching and bring out the best in each other. In France's second largest city Lyon, known as the European "mural capital", there are hundreds of large and small, and all kinds of fine murals, which both reproduce the city's history and record the city's life. Each theme mural is a window and "golden name card" of the city, jointly forming the image of a vivid, intimate and confident city [9]. The mural "Our Roots are still alive", which reflects Palestinians' wish to return to their homeland, is romantic and beautiful. And on the mural, it writes that "the people of Palestine will be free. Everyone has the right to own their homelands and stop the occupation." After the US " $9 \bullet 11$ " attack and the Iraq War, there were also corresponding murals on the street of California, reflecting people's concern over and attitudes towards hot events.

With the impact of multiculturalism, the acceleration of urbanization and the continuous development of urban public space, modern murals have also been rapidly developing in China and there are also a lot of excellent mural works. However, due to the complex relationship between mural art and urban public space, it has not shed of the influence of traditional murals in many aspects during its development, and there is also some dissatisfactory works with varying design levels while not paying attention to the cultural value of modern public art, the integration of public art and the space and environment as well as the relationship between public art and social and cultural ecology. They cannot match with the city's history, spatial characteristics and spirit. Meanwhile, with the development 
of the society, people's improving aesthetic demand and the development of science and technology, corresponding changes must also be made to urban murals so as to serve the society. Thus, there is an urgent need for China's mural arts to develop towards being systematic. In the future, urban mural arts will be more humane and ecological, more diversified and nationalized while integrating the requirements of digital, information and user-friendly design.

There are many issues to be thought about and resolved as how to achieve the expected design effect under the background of a unique and famous historical and cultural city. For example, it is necessary to analyze the features and future changing trend of Xi'an public space, the advantages and problems in the existing murals in Xi'an, propose specific mural design schemes according to the specific urban public space, discuss how to apply the modern materials in the design of urban murals and achieve cross-field art cooperation between urban mural art and the digital field. Only by fully considering these can it possible to design totally natural artistic works perfectly combing the theme and the environment.

As a form of ideological expression, art works themselves can also convey rich ideological contents [10]. As the starting point of the ancient Silk Road, we should think about what kind of murals can express the pride of people of the ancient city; as the builders and promoters of the new Silk Road economic belt, we should also think about what kind of murals can be used to express the support and expectation of people in the ancient city as well as how these mural works can perfectly fit the theme of the times yet with rich cultural heritage, both immersed in history and flourishing in the future [11] so that more and more mural works will become a spiritual symbol and be spread to all over the world from the ancient capital Xi'an, and then impress tourists, laying a solid foundation for Xi'an to really become an international metropolis with rich cultural heritage.

\section{Acknowledgements}

Project Information: Project of Xi'an social science planning fund in 2017

Project No.: 17T60

\section{References}

[1] D Zhang: "China's Modern Art Collection (Murals)", Liaoning Fine Arts Publishing House, Shenyang, 1997.

[2] D.K Du: "The Fantasy, Resurgence and Fission of China's Modern Mural Painting", "Decoration", 1989.2.

[3] F Peng: "Implication of Beauty", China Renmin University Press, Beijing, 2001.

[4] Y.C Zhao, Ceramic Mural Art.[M] Liaoning Fine Arts Publishing House, 2001.

[5] Z Wang, Introduction to Public Art.[M] Beijing University Press, 2007.

[6] Y.S Zhang, The World's Contemporary Public Environmental Art - Ceramics. [M] Hunan Fine Arts Publishing House, 2006.

[7] J.Q Li, "European Medieval Art”, China Renmin University Press, 2010.

[8] W.N Jin, “China's Fine Arts from Wei and Jin Period to Sui and Tang Dynasties”, China Renmin University Press, 2010.

[9] X.S Li, "Exploration of Arts' External Charm - Appreciation and Comparison of Chinese and Western Painting", Culture and Arts Press, 2008.

[10] Catherine Grew, “Art Intervention Space” [M], Guangxi Normal University Press, 2005. 
[11] S.Y Teng, “Aesthetic Mentality Description” [M], China Social Sciences Press, 1985. 